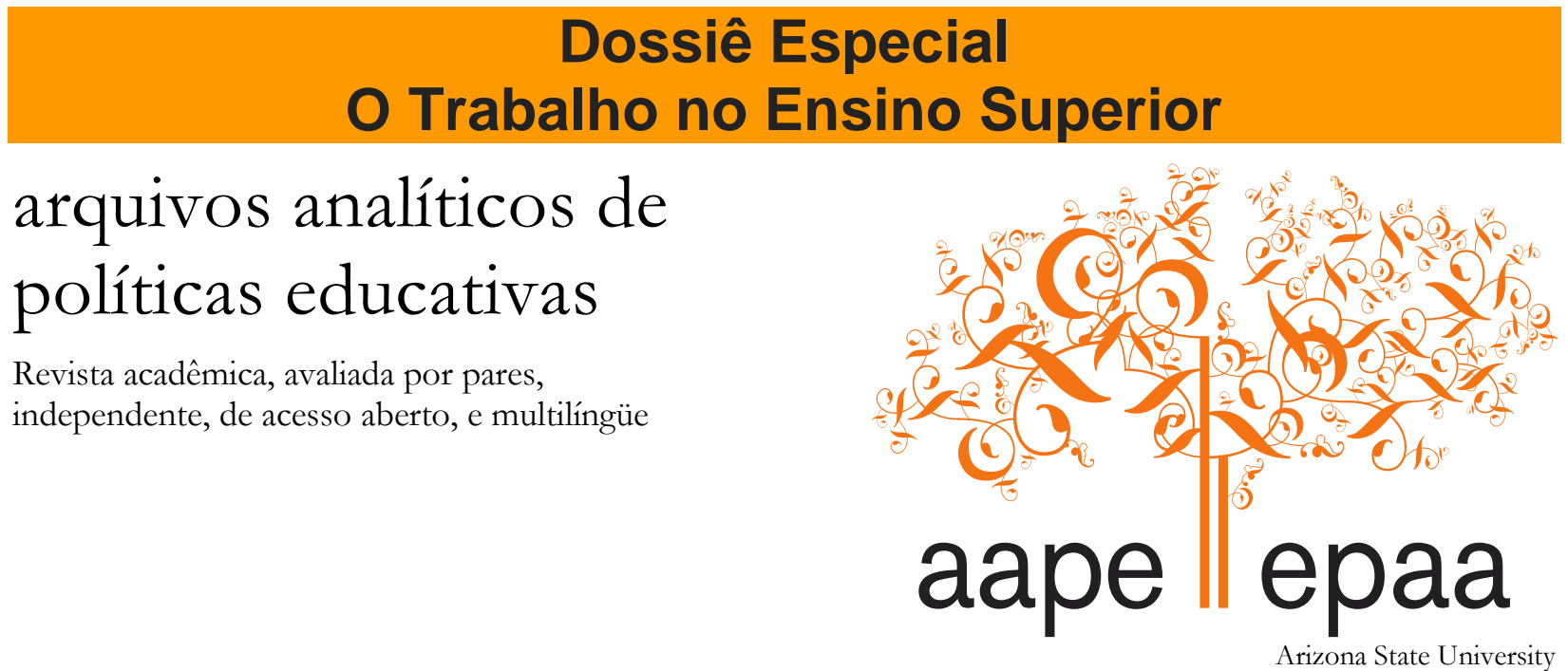

Volume 28 Número 10

20 de janeiro de 2020

ISSN 1068-2341

\title{
Trabalho Docente no Setor Privado da Educação Superior e a Reforma Trabalhista: Destruição de Direitos e Precarização da Vida
}

\author{
Andréa Aranjo do Vale \\ Universidade Federal Fluminense/Rede Universitas/BR \\ Brasil
}

Citação: Vale, A. A. do (2020). Trabalho docente no setor privado da educação superior e a reforma trabalhista: Destruição de direitos e precarização da vida. Arquivos Analíticos de Políticas Educativas, 28(10). https://doi.org/10.14507/epaa.28.4935 Este artigo faz parte do dossiê especial, O trabalho na educação superior, editada por Deise Mancebo, Kátia Maria Teixeira Santorum, Denise Bessa Léda, e Carla Vaz dos Santos Ribeiro.

Resumo: O objetivo deste artigo é apresentar e debater as implicações da dita Reforma Trabalhista (Lei n 13.467/2017) para o trabalho docente nas instituições de ensino superior (IES) privadas brasileiras. É importante ressaltar que, no caso brasileiro, os impactos desta Reforma precisam ser analisados no bojo do processo de mercantilização, empresariamento e privatização da educação superior, que se expressa de muitas formas, mas aqui analisados pelo prisma da formação de grandes conglomerados educacionais e financeirização do setor, articulando um movimento de concentração e centralização de capital e financeirização do setor, com a abertura de capital, presença de fundos de investimento e de empresas de serviços educacionais internacionais, com amplo apoio em um arcabouço político-jurídico e em políticas públicas sustentados pelo Estado em um país com imensas desigualdades sociais e educacionais. Para este texto, utilizou-se pesquisa bibliográfica e pesquisa documental, com consulta ao banco de leis do Senado Federal, e, ainda, consulta a fontes secundárias, como notícias e informações do Sindicato dos Professores de São Paulo (SINPRO-SP), e dos sindicatos patronais, como a 
Associação Brasileira das Mantenedoras de Educação Superior (ABMES) e o Fórum das entidades Representativas do Ensino Superior Particular (FERESP). Com base em uma análise crítica, concluiu-se que a Reforma Trabalhista não apenas atendeu aos interesses do setor privado no sentido de precarização e flexibilização das relações de trabalho - e das condições de existência desses trabalhadores -, mas ainda foi objeto de apreciação dos empresários deste setor e seus especialistas antes de seu encaminhamento legislativo, demonstrando o apoio desse. Palavras-chave: Trabalho Docente; Setor privado; Reforma Trabalhista; Precarização

\section{Teaching work in the private sector of higher education and labor reform: Destruction of rights and precarious life}

Abstract: The purpose of this paper is to present and debate the implications of the so-called Labor Reform (Law $n^{\circ}$ 13.467/2017) for teaching work in private higher education institutions (HEIs). It is important to emphasize that, in the Brazilian case, the impacts of this Reform need to be analyzed in the context of the process of commercialization, entrepreneurship and privatization of higher education, which is expressed in many ways, but here analyzed through the prism of the formation of large educational conglomerates and financialization, articulating a movement of concentration and centralization of capital and financialization of the sector, with the opening of capital, presence of investment funds and international educational services companies, with broad support in a political-legal framework and sustainable public policies by the state in a country with immense social and educational inequalities. For this text, was used bibliographic research and documentary research, with consultation with the Federal Senate law bank, and also with secondary sources, such as news and information from the Teachers Union of São Paulo (SINPRO-SP), and employers' unions, such as the Brazilian Association of Higher Education Matters (ABMES) and the Forum of Representatives of Private Higher Education (FERESP). Based on a critical analysis, it was concluded that the Labor Reform not only met the interests of the private sector in terms of precariousness and flexibility of labor relations and the conditions of existence of these workers -, but was still the object of appreciation by entrepreneurs this sector and its experts prior to its legislative referral, demonstrating their support.

Keywords: Teaching Work; Private Sector; Labor Reform; Precariousness

\section{Trabajo docente en el sector privado de la educación superior y la reforma laboral: Destrucción de derechos y vida precaria}

Resumen: El propósito de este documento es presentar y discutir las implicaciones de la llamada Reforma Laboral (Ley N 13.467 / 2017) para el trabajo docente en instituciones privadas de educación superior (IES) de Brasil. Es importante destacar que, en el caso brasileño, los impactos de esta Reforma deben analizarse en el contexto del proceso de comercialización, emprendimiento y privatización de la educación superior, que se expresa de muchas maneras, pero aquí se analiza a través del prisma de la formación de grandes conglomerados educativos y la financiarización. Articulando un movimiento de concentración y centralización de capital y financiarización del sector, con la apertura de capital, presencia de fondos de inversión y empresas de servicios educativos internacionales, con amplio respaldo en un marco político-legal y políticas públicas sostenibles. Por el estado en un país con inmensas desigualdades sociales y educativas. Para este texto, utilizamos la investigación bibliográfica y la investigación documental, con consulta con el banco de leyes del Senado Federal, y también con fuentes secundarias, como noticias e información del Sindicato de Maestros de São Paulo (SINPRO-SP), y sindicatos de empleadores, como la Asociación Brasileña de Mantenedores de la Educación Superior (ABMES) y el Foro de Representantes de la Educación Superior Privada (FERESP). 
Sobre la base de un análisis crítico, se concluyó que la Reforma Laboral no solo satisfizo los intereses del sector privado en términos de precariedad y flexibilidad de las relaciones laborales, y las condiciones de existencia de estos trabajadores, sino que también fue objeto de apreciación por parte de los empresarios. Este sector y sus expertos antes de su derivación legislativa, demostrando su apoyo.

Palabras-clave: Trabajo docente; Sector privado; Reforma laboral; Precariedad

\section{Introdução}

Logo que a chamada Reforma Trabalhista (Lei n 13.467/2017) foi aprovada, as Instituições Privadas de Educação Superior (IPES), dentre outras instituições, nela se apoiaram para reorganizar, em novos patamares, suas relações trabalhistas: demissões em massa em novos moldes foram efetivadas por diversas empresas de negócios educacionais. Para o trabalho docente na educação superior privada, as consequências foram imediatas: ainda em 2017 várias empresas educacionais empreenderam um reordenamento das relações de trabalho tal como postuladas na lei 13.467/2017, que, praticamente, finda os ataques do capital a Consolidação de Leis do Trabalho (CLT). Este artigo pretende explorar a Reforma Trabalhista e seus impactos sobre o trabalho docente no setor privado da educação superior a partir do entendimento de que estes processos atrelam-se a três movimentos que concretizam a resposta do capital à crise estrutural do sistema sociometabólico do capital desde os anos 1970: a reestruturação produtiva, o ataque às organizações e formas de resistência da classe trabalhadora e a contínua reordenação do Estado, com a progressiva subtração de direitos e ampliação da desproteção aos trabalhadores e trabalhadoras. Para tal tarefa, entretanto, importa esclarecer, de saída, que não se entende a Reforma Trabalhista como um acontecimento pontual, mas como o desdobramento mais recente (e potente) de um extenso e intenso ataque direcionado aos direitos dos trabalhadores e trabalhadoras no Brasil e no mundo. Deste modo, no âmbito desta exposição, serão considerados as mudanças nas relações e condições de trabalho, como, por exemplo, as condições de assalariamento, a existência ou não de mecanismos que impõem a individualização das relações trabalhistas e a própria estrutura jurídica que norteia a (des)proteção aos trabalhadores e trabalhadoras. No caso dos trabalhadores da educação superior brasileira, estes movimentos se combinam em uma particularidade que é o processo mais amplo de mercantilização, privatização e empresariamento da educação, em particular, da educação superior.

Para tanto, este texto se divide em três seções, sem contar esta introdução. A primeira realiza importante discussão sobre o sentido da Reforma Trabalhista em suas linhas centrais, ou seja, entendê-la como momento superior de um ataque que corresponde ao conjunto das respostas do capital à queda da taxa de lucro que se torna expressiva nos anos 1970. A seção seguinte discute a particular configuração da educação superior privada no Brasil contemporâneo, procurando demonstrar o poder dos grandes conglomerados educacionais de pautarem e hegemonizarem a política educacional, com brutais consequências do ponto de vista de um projeto educacional crítico. Enseja-se demonstrar como este empresariado está articulado ao capital em geral no conjunto dos ataques à classe trabalhadora local, demonstrando a voracidade com que rapidamente implementam a Reforma no modo de se relacionar com o trabalhador docente. Na última, apresenta-se as conclusões deste estudo e se aponta para desdobramentos da pesquisa. 


\section{Mudanças no Mundo do Trabalho e a Reforma Trabalhista}

O primeiro ponto deste artigo está situado na necessidade de refletir sobre a situação da educação superior brasileira, considerando um conjunto amplo de processos, sujeitos e movimentos, mas que, no limite, expressa a busca do capital por novos espaços de acumulação, a reordenação do Estado no sentido de criar as condições para a abertura de novos mercados, mas também de criar as amplas condições de acumulação - em especial, o conjunto de ataque aos direitos da classe trabalhadora e na regulação dos patamares de exploração do trabalho necessários a tal ofensiva.

Ao realizar importante análise nessa direção, Dal Rosso (2017) busca empreender uma análise da flexibilidade laboral entendida em sua relação com o tempo - considerando diversas dimensões e distinções conceituais - à luz da teoria do valor. Em tal exercício de pesquisa, ancorada em rica empiria, Dal Rosso (2017) conclui que a flexibilização corresponde a uma desconstrução do trabalho em escala mundial, marcada pela retirada de direitos - característica do neoliberalismo, tal como entendido por Dardot e Laval (2016) - particularmente dos direitos trabalhistas. No caso brasileiro, esse ataque é dotado de particular letalidade, uma vez que essa parca proteção aos trabalhadores e trabalhadoras é de extrema fragilidade e construída também no sentido de atender ao empresariado, como mostrou de modo definitivo Oliveira (2003).

A Reforma Trabalhista efetivada pela Lei n $13.467 / 17$ é constituída pela alteração de mais de 100 artigos da Consolidação das Leis do Trabalho (CLT), apresentada como obsoleta. Deste modo, a Reforma deveria garantir a segurança jurídica, criando um arcabouço jurídico-político modernizado que estimularia que as empresas realizassem investimentos ao permitir que aqueles que se encontram livremente no mercado estabeleçam as regras do contrato por eles mesmos.

Com base na ideia de que o mercado mudou, a Lei 13.467/17 promoveria:

1. a substituição da lei pelo contrato;

2. a adoção de uma legislação mínima, residual, a ser complementada pela negociação/contratação;

3. a criação de diferentes tipos de contrato, distintos do padrão de assalariamento clássico representado pelo contrato por tempo indeterminado;

4. a substituição de direitos universais por direitos diferenciados;

5. a descentralização da negociação coletiva, se possível ao âmbito da empresa;

6. a substituição da intervenção estatal na resolução dos conflitos trabalhistas pela autocomposição das partes (CESIT, IE, UNICAMP, 2017).

Assim, estabelece a prevalência do negociado em relação ao legislado, a flexibilização da jornada de trabalho, novos tipos de contratação - como o trabalho intermitente, e obstaculariza a garantia de gratuidade do processo trabalhista, além de eliminar a obrigatoriedade de que as homologações de demissões aconteçam acompanhadas pelos sindicatos.

Cabe compreender a Reforma Trabalhista como uma das ações envolvidas no conjunto de ataques à classe trabalhadora em movimento desde a crise da acumulação capitalista da década de 1970 e desenhado pelo padrão compósito de dominação burguesa que opera no Brasil. Em termos gerais, trata-se do modo como o capital responde, em termos da composição das relações de exploração do trabalho, à queda da taxa de lucros estruturalmente posta desde os anos 1970 (Mészaros, 2009). Esse modo tem, pelo menos, três linhas distintas, embora coetâneas e articuladas: a introdução/recomposição de dispositivos que permitem o aprofundamento da exploração e dominação dos trabalhadores pelo capital, o ataque às formas de organização e resistência da classe trabalhadora, em especial sindicatos e partidos e a reconfiguração do Estado e de seu arcabouço 
jurídico-político, especialmente no que diz respeito aos elementos de proteção ao trabalhador e grupos subalternos, no caso ora em tela, nos marcos da particularidade brasileira.

Na primeira linha, destaca-se aqui os dispositivos que permitem a precarização das condições de trabalho e a flexibilização das relações de trabalho, como a introdução de mudanças tecnológicas e organizacionais que, no limite, permitem a extração de mais-valor de modo mais intenso. $\mathrm{Na}$ segunda linha, aponta-se para o conjunto de ações compostas de ataques mais ou menos diretos às organizações e às formas de luta da classe trabalhadora. Essas ações vão desde a negação de negociação com os sindicatos das mais diversas categorias por parte do Estado, como aconteceu com os petroleiros em greve no governo de Fernando Henrique Cardoso no ano de 1995, mas também pelo desgaste político e econômico, pela desqualificação das atividades paredistas, e também pela cooptação das entidades sindicais pelo Estado e pelo grande capital, caso especialmente expressivo na gestão de fundos de pensão. Na terceira linha, ressalta-se o modo como o neoliberalismo tem se configurado como racionalidade e empreendido a Reforma do Estado de modo a desregulamentar a proteção social ao trabalho, tanto pela mudança da legislação trabalhista quanto pelos recuos do sistema de garantia de direitos sociais. Deste modo, a Reforma Trabalhista por nós examinada remete ao conjunto das ações que caminham neste sentido, partindo do pressuposto de que, no Brasil, a proteção ao trabalho sempre foi parca, frágil e pouco extensa, como mostra Oliveira (2003).

O período entre 1970 e 1980 foi caracterizado por um conjunto de reestruturações econômica, política e social - gerado pela crise do sistema capitalista que se manifesta pelo colapso da possibilidade do modelo fordista-keynesiano de fazer frente às contradições deste modo de produção. Como réplica a tal colapso, emergiu, apoiado nas Novas Tecnologias da Informação e da Comunicação (NTIC), outro modo de regulação do capitalismo. O neoliberalismo é aqui entendido como a doutrina que configuraria a forma da atuação do Estado de um modo bastante diferente daquele conformado como Estado de Bem Estar Social. Pode-se afirmar que se organizou outra correlação de forças entre capital, trabalho e Estado, engendrando outras formas de figuração e atuação dos Estados nacionais e outros modos de organização do trabalho, e da classe trabalhadora, em uma economia mundial financeirizada.

Harvey (2004) alerta que alterações da esfera produtiva não são uma novidade na história do capitalismo, todavia a acumulação flexível seria abalizada por regimes mais intensos de controle do trabalho (tanto dos mercados de quanto dos processos), produzindo altos níveis de desemprego 'estrutural', ausência ou insignificância de ganhos salariais reais e diminuição do poder sindical. Essas mutações se fariam seguir por contratos flexíveis nos quais predominam a precarização - o trabalho em tempo parcial, temporário e/ou subcontratado, bem como a informalização. Esse é um dos traços centrais da Reforma Trabalhista em um país no qual a informalidade engloba parte muito significativa dos trabalhadores e trabalhadoras, como se verá mais adiante.

De acordo com Dal Rosso (2008), tais mutações assinalam não somente a flexibilização, mas a intensificação do trabalho. Intensificar implica extrair mais resultados - qualitativos ou quantitativos - a partir do maior dispêndio de energia do trabalhador. No atual curso do capitalismo, de acumulação flexível e de lógica toyotista, cruza-se um período de intensificação, seguido e reforçado pela Revolução Tecnológica, que "[...] varre e transforma o trabalho contemporâneo com mil exigências de velocidade, agilidade, ritmo, polivalência, versatilidade, flexibilidade, acúmulo de tarefas e busca incessante de mais resultados" (Dal Rosso, 2008, p. 43). Assim, o ser que trabalha estaria submetido, neste modo de organizar a produção, a um trabalho mais extenuante, causador de maior fadiga, entendida não apenas em termos físicos, mas também intelectuais e emocionais. Fontes (2005), ao examinar-se a extração de mais-valia nos tempos atuais, constata que, sob a dominância da mais-valia relativa, adviria uma (re)atualização de formas antigas de trabalho como condição do alargamento da subsunção real do trabalho ao capital, como, por exemplo, acontece 
com o trabalho domiciliar ou a produção por peças. Entretanto, a divisão e a dispersão da produção para instâncias de pequena escala bem como a segmentação especializada de mercados não derivou, de modo algum, no esboroamento do poder corporativo. Antes, somado à desregulamentação dos mercados, o que se tem é o aumento da tendência monopolista do mercado, com a ampliação da capacidade e poder das corporações, especificamente pelo mecanismo das fusões.

Essas transformações apontam ainda para o crescimento do setor de serviços desde a década de 1970 (Harvey, 2004), em particular nas áreas da “[...] assistência, nas finanças, nos seguros e no setor de imóveis, bem como em outros segmentos como saúde e educação" (Harvey, 2004, p. 149, grifo nosso). Antunes (2000) segue esta afirmação, pois aponta para o crescimento do número de trabalhadores empregados no setor de serviços, do que parte para pensar a necessária (re)definição da morfologia da classe trabalhadora perante novas conformações do mundo do trabalho em sua dinâmica histórica. Esse aumento se liga ainda aos processos de privatização induzidos pelas políticas neoliberais que se concentram especialmente no setor dos serviços como espaços de acumulação de capital.

Estas transformações se fazem sob o predomínio do capital financeiro, sob sua lógica da rentabilidade imediata e especulativa. Chesnais (1999), um grande teórico do tema, assinala que a esfera financeira representa a ponta mais avançada do processo de mundialização do capital, sendo nela que se encontram os montantes mais elevados, maior mobilidade e maior iniciativa do capital em relação ao Estado. Tal mercado procede pela criação de instrumentos completamente novos, em termos de história econômica, que provocaram a desregulamentação do sistema financeiro erigido a partir dos anos 1930, com o auxílio precioso das políticas neoliberais tal como aplicadas desde o fim dos anos 1970.

Grosso modo, importa ressaltar com que o atual modo de operar do capitalismo tem o capital portador de juros no centro das relações econômicas (Chesnais, 2005). Ao buscar precisar o que significaria a pressão do capital portador de juros sobre o desempenho da economia mundial, Chesnais recompõe as etapas da acumulação financeira desde meados dos anos 1950 nos EUA e 1960 na Europa, a partir da contínua e profunda interpenetração entre capital produtivo e finança. Embora tal processo não possa ser recuperado aqui em toda sua extensão e com profundidade, há dois elementos que se faz mister ressaltar: o modo como a dívida foi o mecanismo que ampliou a dominação política e econômica dos países centrais sobre a periferia, impondo violentos ajustes fiscais - implicando o represamento do orçamento para a educação superior de caráter público em todas as esferas -, mas também o fato de que os serviços essenciais se apresentam como áreas extremamente lucrativas para o capital portador de juros, uma vez que são necessários à sobrevivência e à reprodução da classe trabalhadora, como a infraestrutura, a saúde, a previdência e, claro, a educação. Assim, fica claro o interesse deste capital nestes ramos de atuação - são espaços profícuos de acumulação capitalista, o que, no conjunto, justifica sua privatização extensiva e intensiva e a exploração direta pelo capital portador de juros.

Assim, no caso brasileiro, assistimos desde meados dos anos 2000 a outro momento da privatização, da mercantilização e do empresariamento da educação superior: a consolidação de grandes conglomerados educacionais, alguns de capital aberto em Bolsa de Valores (Kroton, Estácio, Ânima e Ser Educacional), grupos internacionais de capital fechado ou aberto que passaram a adquirir instituições brasileiras de modo total ou em parte (Laureate Education, Wyden Educacional) e, ainda, grupos grandes que não abriram o capital (Universidade Paulista - UNIP, Universidade Nove de Julho - Uninove e Universidade Tiradentes) como mostra Chaves (2019).

Esse regime também demandará uma alteração das formas de atuação do Estado. Foi a doutrina neoliberal que forneceu a linha-mestra para estas mudanças. Pode-se afirmar que o neoliberalismo, como discurso, seria a leitura e a proposta mais "congruente" com as demandas alicerçadas nos interesses comuns da burguesia na dinâmica capitalista que então se anunciava, 
expondo e fundamentando as ações mais apropriadas a tais demandas. O ideário neoliberal consolidado a partir de 1947, em torno do economista Friedrich Hayek e o grupo de intelectuais conservadores reunidos no grupo de Mont Pèlerin, emerge como uma resposta mais contígua ao Estado de Bem-Estar Social que se segue à Segunda Guerra Mundial. Mas as possibilidades reais para o protagonismo dessa política econômica só se apresentou com a crise de sobreprodução capitalista nos países desenvolvidos a partir de 1973, marcado pela recessão, altas taxas de inflação e insignificante crescimento econômico, um cenário de estagflação. Tal conjuntura, a partir deste ideário, teria como causa o excessivo poder dos sindicatos bem como os gastos sociais do Estado, o que só poderia ser sanado, destarte, pela desregulamentação do mercado, principalmente no que tange ao capital portador de juros, além de barrar o poder sindical e ajustar os gastos do Estado social. A saída da crise se daria inicialmente pela recuperação de uma espécie de "taxa natural de desemprego" (Anderson, 1995, p. 11).

Assim são eleitos Margareth Thatcher, na Inglaterra, em 1979, e de Ronald Reagan nos Estados Unidos, em 1980, e o neoliberalismo tornou-se "prática de política econômica" (Paulani, 2006, p. 72). Com Helmut Kohl na Alemanha, em 1982, tem-se a chegada ao poder de uma direita ultraliberal na quase totalidade do capitalismo avançado europeu. Para os países periféricos, caso de Chile e Brasil, o receituário neoliberal chega via ditaduras e com a elaboração estabelecida pelo Consenso de Washington.

A política neoliberal agencia a desregulamentação dos mercados e a adoção de medidas antisindicais que funcionam como um relevante operador para o novo grau de flexibilidade exigido no capital mundializado. Tais medidas somam-se a uma densa reforma administrativa e política dos Estados e os eleva a um novo papel: a suposta "intervenção mínima" na área econômica (em termos de regulação dos movimentos do capital, bem entendido) assim como o pouco investimento social e, simultaneamente, a enérgica atuação na desregulamentação dos mercados, sobretudo no que diz respeito ao capital especulativo, o que significou, para os países periféricos endividados, Brasil aí incluído, um aprofundamento de sua condição de dependente em novos patamares. Entende-se aqui, portanto, como estado neoliberal, de acordo com Harvey (2008, p. 17), “[...] o tipo particular de aparelho de Estado cuja missão fundamental foi criar condições favoráveis à acumulação lucrativa de capital pelos capitalistas domésticos e estrangeiros".

Os ataques às formas de organização e resistência da classe trabalhadora têm muitas facetas. A primeira é exatamente a quebra com o pacto do tipo keynesiano ou, no caso brasileiro, mesmo com pactos populistas, como aconteceu durante o governo FHC, por exemplo. Elas são postas em jogo quando capital e Estado recusam a negociação, reprimem a luta, prolongam paralisações, tornando-as custosas aos trabalhadores. As lutas dos trabalhadores também são desqualificadas publicamente, bem como suas demandas são apresentadas como oriundas de privilegiados. Seus movimentos são qualificados como baderna, balbúrdia, bagunça, caso policial. O terceiro ponto reside no desmanche dos mecanismos de proteção ao trabalhador contidos na regulamentação do mercado e pela via da precarização das relações de trabalho pela introdução de modificações no arcabouço jurídico-político, tal como é o caso da Reforma Trabalhista.

As formas de organização da classe trabalhadora, como os sindicatos, por exemplo, que também são duramente afetadas pela reestruturação produtiva, uma vez que dependiam da organização fabril (reunião de trabalhadores em grandes plantas), como no caso fordista, para se viabilizarem. Também para Antunes (2000), e para Fontes (2005), uma vez não laborando mais juntos, os trabalhadores deixam de ser reconhecer como iguais (pertencentes à mesma classe). Também concorre para a desmobilização, o fato do controle exercido sobre os trabalhadores ocorrer em condições mais opacas, especialmente quando se expressa pelo viés tecnológico porém, de modo algum ausente - o que obstaculariza a visão da classe antagônica, fundamental para o reconhecimento da luta de classes que anima o capitalismo (Oliveira, 1987). Além disso, não é 
desprezível que, neste panorama, a competição entre os trabalhadores se desenhe como forma de interação entre eles, inviabilizando a percepção dos companheiros como tais (Fontes, 2005).

No caso da educação superior no Brasil, estes mecanismos parecem se combinar de modo particularmente trágico tanto para os estudantes, mas especialmente para aqueles que neles trabalham.

\section{O Setor Privado da Educação Superior no Brasil e a Reforma Trabalhista}

O setor privado da educação superior brasileira detém não apenas a predominância numérica sobre o setor público desde a ditadura empresarial-militar (cerca de 75\% das matrículas, de acordo com o Censo de 2017), mas também a hegemonia política, o que significa que este setor tem se organizado em sujeitos coletivos (ABMES, Fórum das Entidades Representativas do Ensino Superior Particular - FERESP, dentre outros), de modo a atuar junto ao Executivo, ao Legislativo e ao Judiciário para pautar os marcos regulatórios e as políticas públicas. Os documentos revelam a intensa proximidade entre este empresariado e sucessivos governos, permitindo pensar que se trata de uma política de Estado. Dentre estes documentos, aponta-se aqui para a presença de sucessivos ministros da Educação nos Congressos organizados pelo FERESP (Congresso Brasileiro da Educação Superior Particular) e para a existência de Grupos de trabalho junto com o Ministério da Educação (MEC), com o Conselho Nacional de Educação (CNE), por exemplo, que funcionam como articulações para o direcionamento das políticas educacionais.

Embora essa expansão se desenhe ainda nos anos 1990, desde meados dos anos 2000, o processo de mercantilização, empresariamento e mercantilização da educação superior atinge um novo patamar. As empresas de serviços educacionais, como desde então se denominam, iniciam processos de reengenharia e enxugamento, de transição de gestões familiares para gestões profissionais (contando, muitas vezes, com empresas de consultoria), de compras de mantenedoras/instituições, em uma espiral que atinge um momento único por volta de 2007, quando grandes grupos abrem seu capital em Bolsa de Valores, mas, também, grupos, fundos e empresas internacionais também começam a atuar no país (Chaves, Vale \& Almeida, 2013). Apontamos para o fato de que este setor é hegemonizado pelas instituições de caráter mais abertamente mercantil, segmento este que tem dirigido a política educacional brasileira, como expressa o PNE 2014-2024, por exemplo, mas não unicamente.

Foi este mesmo empresariado que demonstrou claro interesse na Reforma Trabalhista. Em entrevista ao jornal Valor Econômico, consta:

"A reforma trabalhista poderá gerar ganhos para a companhia," disse o presidente da Kroton, Rodrigo Galindo. Segundo ele, em um levantamento preliminar foram encontrados 447 pontos em que é possivel obter ganhos com a aplicaşão das novas regras. "Pela legislação anterior, o professor que dava aulas à noite não poderia dar aulas também pela manhã mas, com a nova regra, isso será possível", disse ele, como um exemplo de alterações que poderão vir a ser aplicadas (Koike, 2017, grifos nossos).

Todavia, mais reveladora seja talvez seja a matéria publicada pela Associação Brasileira de Mantenedoras da Educação Superior (ABMES). Na tentativa de orientar seus associados, a ABMES apresenta a avaliação da Reforma Trabalhista e seus impactos no setor educacional realizada pelo diretor do Centro Brasileiro de Produtividade Institucional - CBPI Produtividade Institucional -, Emerson Casali, e pelo especialista em Direito do Trabalho, Diego Muñoz. A reportagem possui um tamanho razoável, mas é importante destacar algumas falas por seu caráter revelador: "o diretor da CBPI Produtividade Institucional avalia a reforma como positiva para as IES ao aproximar mais as 
regras trabalhistas das necessidades de negócio, ampliando dessa forma as oportunidades" (ABMES, 2017, grifos nossos).

Aqui fica evidente que a Reforma Trabalhista é vista pelo setor empresarial da educação superior por tornar possível que a empresas de serviços educacionais realizem contratações de acordo com suas necessidades. Segundo Dal Rosso (2017), no segmento da educação, constata-se a larga presença da contratação por hora lecionada, implicando flexibilização laboral. No caso da educação superior no país, para dar uma ideia dessa dimensão, o Censo da Educação Superior de 2018 (INEP, 2019) traz os seguintes dados: no setor privado, são 210.606 docentes em exercício. Destes, $57.882(27,5 \%)$ estão registrados em regime integral. Em regime parcial, são 89.339 docentes $(42,4 \%)$. Os horistas somam 63.385 docentes (30,1\%). Juntos, tempo parcial e horistas somam $72,5 \%$, revelando a predominância dos regimes de trabalho mais precarizados em termos salariais e de condições de trabalho.

Ainda segundo Casali, a reforma permitirá que as IES façam uma melhor gestão da jornada de trabalho, o que implicará otimização da produtividade. Para ele, a medida gerará ganhos para empresas e trabalhadores. Dentre as mudanças nas jornadas de trabalho, o diretor destaca a questão das horas in itinere. Anteriormente, o itinerário feito por um trabalhador em veículo próprio da empresa contratante era registrado como jornada de trabalho quando o deslocamento até o serviço era de difícil acesso e sem a possibilidade de transporte público. A reforma elimina a obrigatoriedade desse pagamento (ABMES, 2017, grifos nossos).

Aqui fica patente, apesar da tentativa de mistificação presente no discurso do consultor, que a vantagem da Reforma Trabalhista em relação à jornada de trabalho está na diminuição daquilo que deve ser pago ao trabalhador. Como afirma o dossiê elaborado pelo Grupo de Trabalho da Reforma Trabalhista do Centro de Estudos Sindicais e Economia do Trabalho (CESIT) do Instituto de Economia (IE) da Universidade Estadual de Campinas (UNICAMP), trata-se de redução dos custos das empresas subtraindo tempo de vida do trabalhador, o que é agravado pelo fato de que: "Em muitas atividades, especialmente no meio rural, embarcado ou em regiões de difícil acesso, o trabalhador depende do transporte fornecido pela empresa. Ao desconsiderar o deslocamento, a empresa também está se isentando de qualquer risco durante o percurso" (CESIT, IE, UNICAMP, 2017, p. 46).

A reforma trabalhista também proporcionará novas possibilidades de contratação, seja ela direta, seja indireta, viabilizando modelos mais flexíveis e produtivos. Como exemplo, Casali cita a maior flexibilização do modelo de contratação em tempo parcial, a oportunidade de terceirizar a atividade-fim e o trabalho intermitente. O diretor explica que o último poderá resolver a questão do profissional que as empresas demandam de forma mais irregular (ABMES, 2017, grifos nossos).

Aparece aqui como vantagem a flexibilização das relações trabalhistas as formas cada vez mais flexíveis e precárias de contratação e que engendram a diminuição da segurança de da proteção aos trabalhadores e trabalhadoras, processo sempre encoberto por um discurso que apresenta estas mudanças como modernizadoras. O dossiê do CESIT, mais uma vez, aponta que se trata da retirada da já frágil proteção ao trabalho por meio da terceirização, do trabalho temporário, de tempo parcial e da modalidade de contratação intermitente. É a produção do trabalhador just in time (CESIT, IE, UNICAMP, 2017, p. 32). No limite, trata-se da substituição do trabalhador efetivo pelo prestador de serviços.

A partir de agora, as novas regras relacionadas a cargos e remuneração permitirão a renegociação das bases atuais com vantagens tanto para empresas quanto para trabalhadores. "No 
que se refere aos cargos e remuneração, a reforma também elimina alguns problemas e cria a possibilidade de um sistema mais meritocrático, o que também é bom para produtividade", afirma Casali. Um dos exemplos dessas mudanças é que o plano de cargos e salários não precisará de homologação. Além disso, há mudança de critérios de equiparação salarial.

No caso do plano de carreira, a grande alteração é que o critério para promoções e estipulação de salários passa a ser o critério que eu definir, desde que ele seja claro, objetivo e eu digacomo [sic] ele funcionará. Os critérios de merecimento e antiguidade que estavam previstos sumiram. Eles estão lá como recomendações. Posso usar merecimento? Posso. Posso usar antiguidade? Posso. Posso usar alternado? Posso. Mas posso usar um critério como tamanho do empreendimento? Posso.

O especialista em Direito do Trabalho ainda explica que, no que se refere à equiparação salarial, com a reforma há uma mudança no sentido do termo "local", que antes era entendido como cidade ou região metropolitana. Com a reforma, passa- se ao entendimento de local como estabelecimento, unidade (ABMES, 2017, grifos nossos).

Embora afirme que a Reforma Trabalhista traria vantagens para os trabalhadores, ao elencar quais seriam, o consultor aponta elementos que beneficiam as empresas. Neste caso, fica patente o quanto a Reforma Trabalhista afeta a carreira e a remuneração dos trabalhadores, na medida em que o plano de cargos e salários passa a não ser mais homologado pelo Ministério do Trabalho, mas uma proposta das empresas que estabelece, ela mesma, os critérios a serem utilizados para as promoções ou, quando muito, faça parte da negociação coletiva com os sindicatos.

$\mathrm{Na}$ citação acima, fica clara ainda ampliação da extração de mais-valor e o aumento da competição individual entre os trabalhadores e trabalhadoras, uma vez que a equiparação salarial dispositivo que equipara salários de pessoas que exercem as mesmas atividades - passa a ter como elemento definidor um entendimento estreito de local. Se antes se entendia como local a mesma região metropolitana, agora local é o mesmo estabelecimento, ou seja, o paradigma passa a ser o salário pago na mesma unidade acadêmica, não sendo possível, por exemplo, tomar como parâmetro para a equiparação a mesma função desenvolvida em outras unidades da mesma região ou mesmo outras empresas.

Segundo o diretor, a negociação coletiva ficou mais ampla, com muitos temas que, a partir de agora, podem ser negociados. "Vamos negociar alguns temas imediatamente, outros com um prazo maior. Mas há muito para negociar", garante No que se refere ao encerramento de contratos e justiça trabalhista, Muñoz cita como um exemplo a homologação sindical em rescisão, que deixa de ser obrigatória - algo que, para o especialista, representa um avanço no que se refere a desburocratização.

De acordo com Muñoz, a reforma irá "ajudar" o Judiciário, o Executivo e o Legislativo no que se refere a questões trabalhistas. A ideia é tirar do Judiciário a discussão e deixar que ela fique entre sindicatos e empregadores, sindicatos e empregados. Esse é, vamos dizer, o viés principal da reforma (ABMES, 2017, grifos nossos).

A citação acima torna gritante a questão central: o enfraquecimento dos sindicatos como instâncias de defesa dos direitos dos trabalhadores e trabalhadoras. Ao negar a obrigatoriedade da homologação das rescisões pelos sindicatos, estes passam a ter um papel reduzido, ao mesmo tempo em que se enfraquece o recurso à Justiça do Trabalho.

Deste modo, não há dúvida de que, como assinala Braga (2017), a Reforma Trabalhista é um ponto-chave da guerra da burguesia contra o povo pobre e trabalhador. Tendo como marco jurídico a lei no. 13.467/17, que mexeu em mais de 100 artigos da Consolidação das Leis Trabalhistas (CLT 
- 1943), trata-se de um conjunto de mudanças traz como elementos centrais a prevalência do negociado sobre o legislado (o que afeta, por sua vez, afeta profundamente os sindicatos), a flexibilização da jornada de trabalho, novas modalidades de contratação - como o trabalho intermitente, por exemplo -, e a ameaça à garantia de gratuidade do processo trabalhista, além de desobrigar as homologações de demissões de acontecerem acompanhadas pelos sindicatos das categorias, somando-se à precarização das relações de trabalho alcançada graças à ampliação e expansão das terceirizações, tal como chancelado na Lei 13.429/2017. Sobre o primeiro ponto, sinaliza Braga (2017):

No entanto, do ponto de vista da essência do projeto, isto é, a dominância do negociado sobre o legislado, é importante destacar que dos cerca de 13.000 sindicatos atuantes no setor privado existentes hoje no país, a esmagadora maioria funciona como uma espécie de fiscal da CLT, pois, simplesmente não tem condições de negociar com as empresas benefícios reais para os trabalhadores.

Neste contexto, afirmar a dominância do negociado significa eliminar, em termos práticos, muitas conquistas históricas da classe trabalhadora brasileira. $\mathrm{O}$ avanço da mercantilização do trabalhador levará, fatalmente, ao aumento da insegurança das próprias relações trabalhistas. Afinal, imaginem o que não aconteceria se, subitamente, os trabalhadores representados por um sindicato inexpressivo percebessem que seus representantes assinaram um acordo que, em termos práticos, acabará com o décimo terceiro salário, etc. A aprovação da contrarreforma criará uma situação potencialmente explosiva no país, com um compreensível aumento da violência nas relações de trabalho.

Como mostra a reportagem supracitada, essa violência rebate já de saída sobre os docentes: há muito a negociar...

Altera a estrutura do mercado de trabalho e dificulta o recurso à justiça do trabalho, sob a retórica de que tais modificações favoreceriam a retomada do crescimento e a ampliação do número de vagas no mercado, retórica esta que já se prova falsa. O primeiro ponto a desabar é a retórica que cercou a Reforma: de que ela era necessária para o aumento no número de empregos. Segundo o IBGE, em fevereiro de 2019, a taxa de desemprego no país ficou em 12,4\% no trimestre então encerrado, atingindo 13,1 milhões de pessoas, indicando redução da atividade econômica. O mercado também já vem reajustando - para menos - a projeção do Produto Interno Bruto (PIB) para o ano de 2019: 1,29\%, na $12^{\circ}$ queda consecutiva, configurando um quadro de estagflação. Importa ainda ressaltar que tal quadro reforça o ajuste fiscal, atrelado à Lei de Responsabilidade Fiscal e ao teto orçamentário demarcado pela Emenda Constitucional 95/2017, com cortes orçamentários que atingem sobremaneira as políticas sociais, com destaque para as universidades federais, os institutos e colégios federais, bem como o conjunto da educação básica, apoiado em um discurso que desqualifica essas instituições e suas comunidades, contaminando as redes sociais com notícias falsas e ataques violentos.

Seu efeito sobre o nível de formalização do vínculo de trabalho também é perverso: em 2016, antes da Reforma Trabalhista, 35,6 milhões trabalhadores estavam na informalidade. Já em 2017, após a Reforma e suas promessas de ampliação do emprego, esse número cresceu para 37,3 milhões de trabalhadores, totalizando $40,8 \%$ de toda a população ocupada (que exerce alguma atividade remunerada) no país. E, pior, o que os números mostram é a ampliação da informalidade, uma vez que é esta a porta de entrada para a ocupação (obtenção do sustento).

Os efeitos sobre a categoria docente têm sido deletérios: seja pelas periódicas demissões massivas, seja pelo rebaixamento/inconstância de sua condição salarial, seja por trabalhar nesses grupos, naquelas instituições que, eventualmente entram no mesmo processo (adquiridas, fusionadas 
ou preparando-se para tal) ou por pertencerem a instituições que, em concorrência com os grandes conglomerados, sacrificam imensamente estes trabalhadores e trabalhadoras, não pagando décimoterceiro salário, nem depositando INSS ou FGTS.

O grupo Estácio demitiu, ao fim de 2018, 1.200 professores, deslocando as homologações para suas próprias dependências, o que só foi revertido pelo Sindicato dos Professores do Município do Rio de Janeiro e Região (SINPRO-RJ) em ação jurídica, enquanto o grupo Laureate parece ter demitido 100 dos 150 docentes que integravam sua equipe de ensino a distância (EaD). E as demissões continuaram no ano de 2018. Ainda segundo denúncia do SINPRO-SP, o Grupo Laureate realizou ao final do primeiro semestre de 2019, uma demissão massiva - 200 professores em todas as instituições controladas pelo Grupo (Centro Universitário das Faculdades Metropolitanas Unidas, FIAM-FAAM e Anhembi Morumbi). A Universidade Nove de Julho (seriam 350 demissões) e a Universidade São Judas Tadeu também realizaram demissões substantivas. A Pontifícia Universidade Católica do Paraná (PUC-PR) reelaborou o plano de cargos e salários em um processo conturbado, conforme denúncias do Sindicato dos Professores do Ensino Superior de Curitiba e Região Metropolitana (SINPES).

Do outro lado, neste momento, o SINPRO-SP está com audiências marcadas em ações judiciais coletivas contra as Faculdades Oswaldo Cruz (FOC) e o centro universitário Unisant'Anna por: “[...] multa por atraso no pagamento dos salários, como garantido na Convenção Coletiva, e depósitos de FGTS em atraso. Na Oswaldo Cruz também está sendo exigido o pagamento integral do 13 Salário de 2018”" (SINPRO-SP, 2019a). Já na Universidade Metodista, depois de 19 dias de greve em fins de maio, as aulas foram retomadas depois de cumprido um acordo que definia:

a) regularizar o pagamento dos salários de abril/ 2019 de todos os empregados até o dia 06.06.2019; b) pagar todos os salários de maio/2019, de todos os empregados, dentro do mês de junho/2019, e os salários de todos os empregados, alusivos ao mês de junho, serão pagos até o dia 10.07.2019; c) cumprir o parcelamento do FGTS já acordado e regularizar outras diferenças pendentes; d) regularizar a quitação dos débitos de empréstimos consignados dos empregados e do vale-alimentação em até 120 dias, sendo o primeiro pagamento no dia 20.06.2019, compreendendo a parcela do próprio mês e uma parcela atrasada, ou seja, duas parcelas mensais, a partir de 20.06.2019; e) não desconto dos dias parados, mediante a reposição das aulas; $\mathrm{f}$ ) retorno imediato dos docentes ao trabalho (SINPROSP, 2019c, grifos nossos).

Em geral, também há perda da autonomia, invasão do tempo livre pelo tempo de trabalho, controle do trabalho (tanto do conteúdo como da forma do trabalho, mas também do tempo com formas cada vez mais refinadas), apenas para citar algumas consequências. Como mostra Dal Rosso (2017), a flexibilização da jornada de trabalho tem sido orientada de modo a extrair maior mais-valia do trabalhador, embora apareça, muitas vezes, como liberação ou autonomia.

\section{Conclusões}

E parece que o pior ainda está por vir... A Reforma Trabalhista realizada no governo Temer foi a primeira de um novo ciclo reformista de caráter regressivo que inclui, ainda, a Emenda Constitucional 95, que estabelece um novo regime fiscal com teto de gastos, a Reforma da Previdência, já aprovada em segundo turno no Senado Federal, e Reforma Administrativa, só para citar as mais recentes. Ou seja, o momento é de um novo ciclo de ataque aos direitos dos trabalhadores e trabalhadoras, marcando uma deterioração das condições e relações de trabalho, materializando-se como precarização da vida. 
Neste artigo, foi possível indicar que a Reforma Trabalhista veio ao encontro de expectativas dos empresários da educação superior, com a previsão de muitas possibilidades de aplicação da nova Lei. Além disso, o artigo aponta para os principais impactos já experimentados a partir da Reforma, com ênfase no número de demissões efetivadas a partir do final de 2017 e na alteração de planos de cargos e salários, especialmente por parte de grandes empresas educacionais, enquanto, em outras instituições, tem-se o atraso no pagamento de salários, a rescisão de contratos sem pagamento de verbas rescisórias, dentre outros exemplos.

Verifica-se que, no conjunto, tais ações ampliam a flexibilidade das relações de trabalho e precarizam as condições de assalariamento e de vida de uma grande massa de trabalhadores, em um quadro em que a educação superior brasileira está nas mãos de um setor privado hegemonizado por grandes conglomerados de serviços educacionais, os maiores com capital aberto em Bolsa de Valores e presença de fundo público no financiamento de suas atividades, com majoritária preferência pela contratação pelas vias mais precárias (tempo parcial e horista). A Reforma Trabalhista, portanto, expõe o conjunto de trabalhadores dessas instituições a formas ainda mais vulneráveis de contratação e processos de assalariamento ainda mais aviltantes.

Dois pontos se revelam essenciais para a continuidade dessa pesquisa: a necessidade de acompanhar a adoção ou não de formas de contratação como o contrato intermitente, mas também investigar profundamente as condições de assalariamento desta categoria, uma vez que a minoração dos regimes de trabalho pode apontar para a precariedade da remuneração, que implica, necessariamente, em precariedade da vida.

\section{Referências}

ABMES. (2017, novembro 15). Reforma Trabalhista: Quais serão os reflexos para as IES? Notícias. Recuperado de http://abmes.org.br/noticias/detalhe/2565/reforma-trabalhista-quais-seraoos-reflexos-para-as-ies-.

Anderson, P. (1995). Balanço do neoliberalismo. In: E. Sader (Org.), Pós-neoliberalismo: As políticas sociais e o Estado democrático (pp. 9-23). Rio de Janeiro: ed. Paz e Terra.

Antunes, R. (2006). Adeus ao proletariado? Ensaio sobre as metamorfoses e a centralidade do mundo do trabalho. Campinas: Editora da Universidade Estadual de Campinas.

Ávila, S. O. de; Léda, D. B.; \& Vale, A. A. do. (2012). Configurações do setor privado-mercantil na expansão da educação superior privada: Notas para análise do trabalho docente. In: D. Macebo \& J. Dos R. Silva Jr. (Orgs.), Trabalbo docente e expansão da educação superior brasileira (pp. 146-182). Rio de Janeiro: EDUERJ.

Braga, R. (2018). O juízo de Vargas. Blog da Boitempo. São Paulo, jan. de 2018. Recuperado de https://blogdaboitempo.com.br/2018/01/03/o-juizo-de-vargas/.

BRASIL. (2017). Lei No 13.467, de 13 de julho de 2017. Altera a Consolidação das Leis do Trabalho (CLT), aprovada pelo Decreto-Lei no 5.452, de 1o de maio de 1943, e as Leis nos 6.019, de 3 de janeiro de 1974, 8.036, de 11 de maio de 1990, e 8.212, de 24 de julho de 1991, a fim de adequar a legislação às novas relações de trabalho. Brasília.

CESIT. IE. UNICAMP. (2017). Contribuição Crítica à Reforma Trabalhista. Campinas, GT Reforma Trabalhista. CESIT, IE, UNICAMP. Recuperado de http://www.cesit.net.br/wpcontent/uploads/2017/06/Dossie-14set2017.pdf.

Chaves, V. L. J. (2019). O ensino superior privado-mercantil em tempos de economia financeirizada. In: F. Cássio (Org.), Educação contra a barbárie: Por escolas democráticas e pela liberdade de ensinar (pp. 67 - 73). São Paulo: Boitempo Editorial. 
Chaves, V. L. J., Vale, A. A. do, \& Carvalho, C. H. A. de. (2014). Expansão privado-mercantil e a financeirização da educação superior brasileira. In: B. Cabrito, L. Cerdeira, A. M. de Castro, \& V. L. J. Chaves (Orgs), Os desafios da expansão da educação em países de língua portuguesa: financiamento e internacionalização (pp.199-220). Lisboa: Educa.

Chesnais, F. (2005). O capital portador de juros: Acumulação, internacionalização, efeitos econômicos e políticos. In: F. Chesnais (Org.), A finança mundializada: Raízes sociais e políticas, configuração, consequências (pp. 35-67). São Paulo: Boitempo,

Chesnais, F. (1999). Introdução geral. In: A mundialização financeira: Gênese, custos e riscos (pp. 11 - 33). São Paulo: Xamã.

Coutinho, C. N. (2007). Gramsci: Um estudo sobre seu pensamento político (3. ed.). Rio de Janeiro: Civilização Brasileira.

Dal Rosso, S. (2017). O ardil da flexibilização: Os trabalhadores e a teoria do valor. São Paulo: Boitempo.

Dal Rosso, S. (2008). Mais trabalho! A intensificação do labor na sociedade contemporânea. São Paulo: Boitempo Editorial.

Dardot, P., \& Laval, C. (2016). A nova razão do mundo: Ensaio sobre a sociedade neoliberal. São Paulo: Boitempo Editorial.

Fontes, V. M. (2005). Reflexões im-pertinentes: História e capitalismo contemporâneo. Rio de Janeiro: Bom Texto.

Harvey, D. (2008). O neoliberalismo: História e consequências. São Paulo: Edições Loyola.

Harvey, D. (2004). A condição pós-moderna. Uma pesquisa sobre as origens da mudança cultural (13.ed.). São Paulo: Loyola.

Koike, B. (2017, dezembro 11). Kroton vê ganhos para a companhia com reforma trabalhista. Valor Econômico. [Versão Digital].

Mészáros, I. (2009). A crise estrutural do capital. São Paulo: Boitempo.

Neves, L. M. W. (2002). Rumos históricos da organização privatista. In: L. M. W. Neves (Org.), O empresariamento da Educação: novos contornos do ensino superior no Brasil dos anos 1990. (pp. 176220). São Paulo: Xamã.

Oliveira, F. de. (2003). Crítica da razão dualista/O ornitorrinco. São Paulo, Boitempo Editorial. Paulini, L. (2005). Modernidade e discurso econômico. São Paulo: Boitempo.

SINPRO-SP. (2019a). Marcadas audiências nas ações contra o UnisantAnna e Faculdades Oswaldo Cruz. Notícias. Recuperado de: http://www.sinprosp.org.br/noticias.asp?id_noticia=35359.

SINPRO-SP. (2019b). SINPROSP convoca assembleia dos professores do Grupo Laureate. Notícias. Recuperado de http://www.sinprosp.org.br/noticias.asp?id_noticia=3556.

SINPRO-SP. (2019c) Professores da Metodista suspendem greve vitoriosa!. Notícias. Recuperado de http:/ /www.sinprosp.org.br/noticias.asp?id_noticia=35269.

Vale, A. A. do (2008). Considerações sobre a organização das IES privadas brasileiras: uma análise das propostas da ABMES - uma entidade representativa do setor privatista para o quadriênio 2007-2011. Trabalbo Necessário, 6(7), Niterói [Versão Digital]. https://doi.org/10.22409/tn.6i7.p4651

Vale, A. A. do (2011). "As faculdades privadas não fazem pesquisa porque não querem jogar dinheiro fora": A trajetória da Estácio de Sá da filantropia ao mercado financeiro. Tese de Doutorado, Programa de Pós-graduação em Políticas Públicas e Formação Humana, Universidade do Estado do Rio de Janeiro, Rio de Janeiro.

Wapshott, N. (2016). KEYNES x HAYEK: A origem e a berança do maior duelo econômico da bistória. Rio de Janeiro: Record. 


\section{Sobre o Autora}

\section{Andréa Araujo do Vale}

Universidade Federal Fluminense/Rede Universitas/BR

andreaaraujodovale@gmail.com

ORCID: https://orcid.org/0000-0001-7142-6445

Professora Adjunta C2 da Escola de Serviço Social da Universidade Federal Fluminense (UFF). Graduada em Comunicação Social com habilitação em Jornalismo pela Universidade Federal Fluminense (UFF) e Mestre em Comunicação e Cultura pela Escola de Comunicação da Universidade Federal do Rio de Janeiro (ECO/UFRJ). Doutora em Políticas Públicas e Formação Humana, em 2011, pelo Programa de Pós-Graduação em Políticas Públicas e Formação Humana pela Universidade do Estado do Rio de Janeiro (PPFH/UERJ). Docente permanente do Programa de Pós-Graduação em Desenvolvimento Regional e Serviço Social da ESS/UFF. Coordenação do Eixo 4 da pesquisa integrada intitulada Políticas, Gestão e Direito à Educação Superior: novos modos de regulação e tendências em construção pós-2013, realizada no âmbito da Rede Universitas/BR.

\section{Sobre as Editoras Convidas}

\section{Deise Mancebo}

Universidade do Estado do Rio de Janeiro

deise.mancebo@gmail.com

http://orcid.org/0000-0001-8312-4495

Doutora em Educação pela Pontifícia Universidade Católica de São Paulo. Professora Titular da Universidade do Estado do Rio de Janeiro. Pesquisadora e professora do Programa de Pósgraduação em Políticas Públicas e Formação Humana. Coordenadora da Rede Universitas/Br.

\section{Kátia Maria Teixeira Santorum}

Universidade do Estado do Rio de Janeiro

katia.santorum@gmail.com

https://orcid.org/0000-0003-2830-157X

Doutora em Saúde Pública pela Escola Nacional de Saúde Pública Sérgio Arouca / Fundação

Oswaldo Cruz (Fiocruz). Professora Adjunta da Universidade do Estado do Rio de

Janeiro. Pesquisadora e professora do Programa de Pós-graduação em Políticas Públicas e Formação Humana.

\section{Carla Vaz dos Santos Ribeiro}

Universidade Federal do Maranhão

carlavazufma@gmail.com

http://orcid.org/0000-0002-5518-9619

Doutora em Psicologia Social pela Universidade do Estado do Rio de Janeiro. Professora Associada da Universidade Federal do Maranhão. Pesquisadora e professora do Programa de Pós-graduação em Psicologia da UFMA. Integrante da Rede Universitas/Br.

\section{Denise Bessa Léda}

Universidade Federal do Maranhão

denise.bessa.leda@gmail.com 
http://orcid.org/0000-0002-8696-6126

Doutora em Psicologia Social pela Universidade do Estado do Rio de Janeiro. Professora da Universidade Federal do Maranhão. Professora permanente e pesquisadora do Programa de PósGraduação em Psicologia da Universidade Federal do Maranhão. Membro da Rede Universitas/Br e do Grupo de Pesquisa Psicodinâmica e Clínica do Trabalho da Associação Nacional de Pesquisa e Pós-graduação em Psicologia.

\section{Dossiê Especial
O Trabalho no Ensino Superior arquivos analíticos de políticas educativas}

Volume 28 Número 10
20 de janeiro 2020
ISSN 1068-2341

\section{(c) (1) (-)}

Los/as lectores/as pueden copiar, mostrar, distribuir, y adaptar este articulo, siempre y cuando se de crédito y atribución al autor/es y a Archivos Analíticos de Políticas Educativas, los cambios se identifican y la misma licencia se aplica al trabajo derivada. Más detalles de la licencia de Creative Commons se encuentran en https://creativecommons.org/licenses/bysa/2.0/. Cualquier otro uso debe ser aprobado en conjunto por el autor/es, o AAPE/EPAA. La sección en español para Sud América de AAPE/EPAA es publicada por el Mary Lou Fulton Teachers College, Arizona State University y la Universidad de San Andrés de Argentina. Los artículos que aparecen en AAPE son indexados en CIRC (Clasificación Integrada de Revistas Científicas, España) DIALNET (España), Directory of Open Access Journals, EBSCO Education Research Complete, ERIC, Education Full Text (H.W. Wilson), PubMed, QUALIS A1 (Brazil), Redalyc, SCImago Journal Rank, SCOPUS, SOCOLAR (China).

Por errores y sugerencias contacte a Fischman@asu.edu

Síganos en EPAA's Facebook comunidad at https://www.facebook.com/EPAAAAPE y en Twitter feed@epaa_aape. 


\section{arquivos analíticos de políticas educativas conselho editorial}

Editor Consultor: Gustavo E. Fischman (Arizona State University)

Editoras Associadas: Andréa Barbosa Gouveia (Universidade Federal do Paraná), Kaizo Iwakami Beltrao, (Brazilian School of Public and Private Management - EBAPE/FGVl), Sheizi Calheira de Freitas (Federal University of Bahia), Maria Margarida Machado, (Federal University of Goiás / Universidade Federal de Goiás), Gilberto José Miranda, (Universidade Federal de Uberlândia, Brazil), Marcia Pletsch, Sandra Regina Sales (Universidade Federal Rural do Rio de Janeiro)

\author{
Almerindo Afonso \\ Universidade do Minho \\ Portugal
}

Rosanna Maria Barros Sá

Universidade do Algarve

Portugal

\section{Maria Helena Bonilla \\ Universidade Federal da Bahia \\ Brasil}

Rosa Maria Bueno Fischer Universidade Federal do Rio

Grande do Sul, Brasil

Alice Casimiro Lopes

Universidade do Estado do Rio de

Janeiro, Brasil

\section{Suzana Feldens Schwertner Centro Universitário Univates Brasil}

Geovana Mendonça Lunardi Mendes Universidade do Estado de Santa Catarina

Flávia Miller Naethe Motta

Universidade Federal Rural do Rio de Janeiro, Brasil

Alexandre Fernandez Vaz

Universidade Federal de Santa

Catarina, Brasil

Regina Célia Linhares Hostins

Universidade do Vale do Itajaí,

Brasil

\section{Alfredo Macedo Gomes \\ Universidade Federal de \\ Pernambuco Brasil}

Jefferson Mainardes

Universidade Estadual de Ponta

Grossa, Brasil

Jader Janer Moreira Lopes

Universidade Federal Fluminense

e Universidade Federal de Juiz de Fora, Brasil

\section{Debora Nunes \\ Universidade Federal do Rio \\ Grande do Norte, Brasil}

Alda Junqueira Marin

Pontifícia Universidade Católica de São Paulo, Brasil

Dalila Andrade Oliveira

Universidade Federal de Minas

Gerais, Brasil
José Augusto Pacheco

Universidade do Minho, Portugal

Jane Paiva

Universidade do Estado do Rio de Janeiro, Brasil

Paulo Alberto Santos Vieira Universidade do Estado de Mato Grosso, Brasil

Fabiany de Cássia Tavares Silva Universidade Federal do Mato Grosso do Sul, Brasil

\section{António Teodoro}

Universidade Lusófona

Portugal

\section{Lílian do Valle}

Universidade do Estado do Rio de Janeiro, Brasil

\author{
Alfredo Veiga-Neto \\ Universidade Federal do Rio \\ Grande do Sul, Brasil
}




\section{archivos analíticos de políticas educativas consejo editorial}

Editor Consultor: Gustavo E. Fischman (Arizona State University)

Editores Asociados: Felicitas Acosta (Universidad Nacional de General Sarmiento, Argentina), Armando Alcántara Santuario (Universidad Nacional Autónoma de México), Ignacio Barrenechea, Jason Beech (Universidad de San Andrés), Angelica Buendia, (Metropolitan Autonomous University), Alejandra Falabella (Universidad Alberto Hurtado, Chile), Carolina Guzmán-Valenzuela (University of Chile), Veronica Gottau (Universidad Torcuato Di

Tella), Antonio Luzon, (Universidad de Granada), José Luis Ramírez, (Universidad de Sonora), Paula Razquin, Axel Rivas (Universidad de San Andrés), Maria Veronica Santelices (Pontificia Universidad Católica de Chile), Maria

Alejandra Tejada-Gómez (Pontificia Universidad Javeriana, Colombia)

Claudio Almonacid

Universidad Metropolitana de

Ciencias de la Educación, Chile

Miguel Ángel Arias Ortega

Universidad Autónoma de la

Ciudad de México

Xavier Besalú Costa

Universitat de Girona, España

Xavier Bonal Sarro Universidad

Autónoma de Barcelona, España

Antonio Bolívar Boitia

Universidad de Granada, España

José Joaquín Brunner Universidad Diego Portales, Chile

Damián Canales Sánchez

Instituto Nacional para la

Evaluación de la Educación, México

Gabriela de la Cruz Flores

Universidad Nacional Autónoma de México

Marco Antonio Delgado Fuentes

Universidad Iberoamericana,

México

Inés Dussel, DIE-CINVESTAV, México

Pedro Flores Crespo Universidad Iberoamericana, México
Ana María García de Fanelli

Centro de Estudios de Estado y

Sociedad (CEDES) CONICET, Argentina

Juan Carlos González Faraco

Universidad de Huelva, España

María Clemente Linuesa

Universidad de Salamanca, España

Jaume Martínez Bonafé

Universitat de València, España

Alejandro Márquez Jiménez Instituto de Investigaciones sobre la Universidad y la Educación, UNAM, México

María Guadalupe Olivier Tellez,

Universidad Pedagógica Nacional,

México

Miguel Pereyra Universidad de

Granada, España

Mónica Pini Universidad Nacional

de San Martín, Argentina

Omar Orlando Pulido Chaves

Instituto para la Investigación

Educativa y el Desarrollo Pedagógico (IDEP)

José Ignacio Rivas Flores

Universidad de Málaga, España

\section{Miriam Rodríguez Vargas \\ Universidad Autónoma de \\ Tamaulipas, México}

José Gregorio Rodríguez

Universidad Nacional de Colombia, Colombia

Mario Rueda Beltrán Instituto de Investigaciones sobre la Universidad y la Educación, UNAM, México

José Luis San Fabián Maroto

Universidad de Oviedo,

España

Jurjo Torres Santomé, Universidad de la Coruña, España

Yengny Marisol Silva Laya

Universidad Iberoamericana, México

Ernesto Treviño Ronzón

Universidad Veracruzana, México

Ernesto Treviño Villarreal

Universidad Diego Portales Santiago, Chile

Antoni Verger Planells Universidad Autónoma de Barcelona, España

\section{Catalina Wainerman}

Universidad de San Andrés, Argentina

Juan Carlos Yáñez Velazco

Universidad de Colima, México 


\section{education policy analysis archives editorial board}

Lead Editor: Audrey Amrein-Beardsley

Editor Consultor: Gustavo E. Fischman (Arizona State University)

Associate Editors: Melanie Bertrand, David Carlson, Lauren Harris, Eugene Judson, Mirka Koro-Ljungberg, Daniel Liou, Scott Marley, Molly Ott, Iveta Silova (Arizona State University)

Cristina Alfaro

San Diego State University

Gary Anderson

New York University

Michael W. Apple

University of Wisconsin, Madison

Jeff Bale

University of Toronto, Canada

Aaron Bevanot SUNY Albany

David C. Berliner

Arizona State University

Henry Braun Boston College

\section{Casey Cobb}

University of Connecticut

Arnold Danzig

San Jose State University

Linda Darling-Hammond

Stanford University

Elizabeth H. DeBray

University of Georgia

David E. DeMatthews

University of Texas at Austin

Chad d'Entremont Rennie Center

for Education Research \& Policy

John Diamond

University of Wisconsin, Madison

Matthew Di Carlo

Albert Shanker Institute

Sherman Dorn

Arizona State University

Michael J. Dumas

University of California, Berkeley

Kathy Escamilla

University ofColorado, Boulder

Yariv Feniger Ben-Gurion

University of the Negev

Melissa Lynn Freeman

Adams State College

Rachael Gabriel

University of Connecticut
Amy Garrett Dikkers University

of North Carolina, Wilmington

Gene V Glass

Arizona State University

Ronald Glass University of

California, Santa Cruz

Jacob P. K. Gross

University of Louisville

Eric M. Haas WestEd

Julian Vasquez Heilig California

State University, Sacramento

Kimberly Kappler Hewitt

University of North Carolina

Greensboro

Aimee Howley Ohio University

Steve Klees University of Maryland

Jaekyung Lee SUNY Buffalo

Jessica Nina Lester

Indiana University

Amanda E. Lewis University of

Illinois, Chicago

Chad R. Lochmiller Indiana

University

Christopher Lubienski Indiana

University

Sarah Lubienski Indiana University

William J. Mathis

University of Colorado, Boulder

Michele S. Moses

University of Colorado, Boulder

Julianne Moss

Deakin University, Australia

Sharon Nichols

University of Texas, San Antonio

Eric Parsons

University of Missouri-Columbia

Amanda U. Potterton

University of Kentucky

Susan L. Robertson

Bristol University
Gloria M. Rodriguez

University of California, Davis

R. Anthony Rolle

University of Houston

A. G. Rud

Washington State University

Patricia Sánchez University of

University of Texas, San Antonio

Janelle Scott University of

California, Berkeley

Jack Schneider University of

Massachusetts Lowell

Noah Sobe Loyola University

Nelly P. Stromquist

University of Maryland

Benjamin Superfine

University of Illinois, Chicago

Adai Tefera

Virginia Commonwealth University

A. Chris Torres

Michigan State University

Tina Trujillo

University of California, Berkeley

Federico R. Waitoller

University of Illinois, Chicago

Larisa Warhol

University of Connecticut

John Weathers University of

Colorado, Colorado Springs

Kevin Welner

University of Colorado, Boulder

Terrence G. Wiley

Center for Applied Linguistics

John Willinsky

Stanford University

Jennifer R. Wolgemuth

University of South Florida

Kyo Yamashiro

Claremont Graduate University

Miri Yemini

Tel Aviv University, Israel 